\title{
Modelling the Composition of Melts Formed During Continental Breakup of the Southeast Greenland Margin
}

\author{
John J. Armitage ${ }^{a, *}$ Timothy J. Henstock ${ }^{a}$ \\ Timothy A. Minshull ${ }^{a}$ \\ a National Oceanography Centre, Southampton, University of Southampton, \\ European Way, Southampton, SO14 3ZH \\ John R. Hopper ${ }^{\mathrm{b}}$ \\ ${ }^{\mathrm{b}}$ Department of Geology and Geophysics, Texas A\&M University, College Station, \\ $T X$
}

5000 words in main text excluding the Appendix, 57 references. Estimated 19 printed pages.

\begin{abstract}
We have developed a generic dynamic model of extension of the lithosphere, which predicts major element composition and volume of melt generated from initial extension to steady state seafloor spreading. Stokes equations for non-Newtonian flow are solved and the mantle melts by decompression. Strengthening of the mantle due to dehydration as melting progresses is included. The composition is then empirically related to depletion. Using a crystallisation algorithm, the predicted primary melt composition was compared with mean North Atlantic mid-ocean ridge basalt (MORB). At steady state, using half spreading rates from 10 to $20 \mathrm{~mm} \mathrm{yr}^{-1}$ and mantle potential temperatures of 1300 to $1325^{\circ} \mathrm{C}$ we predict a major element composition that is within the variation in the mean of North Atlantic MORB.

This model is applied to the Southeast Greenland margin, which has extensive coverage of seismic and ODP core data. These data have been interpreted to indicate an initial pulse of magmatism on rifting that rapidly decayed to leave oceanic crustal thickness of 8 to $11 \mathrm{~km}$. This pattern of melt production can be recreated by
\end{abstract}

Preprint submitted to Elsevier 31 January 2008 
introducing an initial hot layer of asthenosphere beneath the continental lithosphere and by having a period of fast spreading during early opening. The hot layer was convected through the melt region giving a pulse of high magnesian and low silica melt during the early rifting process. The predicted major element composition of primary melts generated are in close agreement with primary melts from the Southeast Greenland margin. The observed variations in major element composition are reproduced without a mantle source composition anomaly.

Key words: Southeast Greenland Margin, major element composition, Large Igneous Province, ridge-hotspot interaction

\section{Introduction}

2 The volume and composition of melt generated by adiabatic decompression is 3 influenced by the potential temperature and upwelling rate of the lithosphere 4 [1]. The breakup of continents can lead to large amounts of magmatism giving 5 large igneous provinces such as that formed around the North Atlantic in the 6 early Tertiary [2-4]. Various models for extension and rifting have been put 7 forward: models in which stretching and buoyancy are imposed but the velocity 8 field is not perturbed by buoyancy, e.g. [5-7]; and more dynamic models, in 9 which the flow of material is subject to internal forces due to density gradients 10 within mantle, e.g. [8-11]. Here we develop a two dimensional dynamic model 11 of rifting that includes melt composition calculations. This model will be used 12 to explore the evolution of volcanic margins and the thermal and chemical 13 nature of the mantle beneath such margins. We shall examine the effect of the 14 initial temperature structure, and early spreading rates upon the evolution of 15 the Southeast Greenland margin, which is in the distal region of the possible 16 Iceland plume track [12].

\footnotetext{
* Corresponding author, Telephone: +44 2380592574

Email address: j.armitage@noc.soton.ac.uk (John J. Armitage).
} 


\subsection{Breakup of the North Atlantic}

The breakup of the North Atlantic is thought to have been influenced by the Iceland hotspot $[13,12]$. In this article we are concerned with understanding the breakup of Southeast Greenland from the Hatton Bank off the west coast of Ireland and UK. The breakup of the North Atlantic took the following scenario: at $61 \mathrm{Ma}$ a thermal plume impacted the margin and delivered warm mantle material to distal portions of the margin away from the plume impact area $[12,14,15]$. Warm mantle material drained along the sublithospheric topography spreading into the distal regions of the margin $[12,16]$. At breakup, between 56 and $53 \mathrm{Ma}[15,17,18]$, the plume continued to feed excess melt generation and active upwelling in the proximal portion of the margin [12]. In the distal regions, warm material was exhausted during breakup and the margin then evolved towards a steady state crustal thickness of between 8 and $11 \mathrm{~km}$ [12]. By 45 Ma excess magmatism was confined to regions around Iceland. Therefore the anomalously thick crust observed off Southeast Greenland [4] is possibly explained by the presence of such a hot layer beneath the lithosphere.

Studies of global mid-ocean ridge basalt (MORB) find that mean primary magma has between 10 and $15 \% \mathrm{MgO}$, and that the primary magma compositions correlate with the axial depth of the ocean ridge [20]. However, primary magmas from Southeast Greenland have $\mathrm{MgO}$ contents of up to $18 \%$ and high $\mathrm{FeO}$ contents of up to $14 \%$ [19]. Such melt compositions may be attributed to source heterogeneity associated with the ancestral Iceland plume, increased melt fraction due to the presence of a thermal anomaly, or both $[21,22]$.

\subsection{Drilling off Southeast Greenland}

The Ocean Drilling Program (ODP) cored the Southeast Greenland margin during legs 152 and 163 (see Figure 1). The transition within site 917 from thick silicic flows through a sandstone layer to units of olivine basalt and picrite marks the final stage of breakup $[23,24]$. Basalts from the upper series at site 917 have not been dated although the setting of this series suggests an 
age of $56 \mathrm{Ma}$ or older $[25,26]$. Basalts recovered from the upper series have high concentrations of magnesium oxide (see Table 1; [19]) and have been inferred to be close to primary [27]. It is believed that these units were rapidly erupted through a system of fissures rather than stored within magma chambers [22]. Furthermore it is suggested that such aphyric picrite with $18 \% \mathrm{MgO}$ would have had an eruption temperature of $1380^{\circ} \mathrm{C}$, which implies a mantle potential temperature 1500 to $1600{ }^{\circ} \mathrm{C}[28,24]$.

Site 990 lies fractionally further off-shore and was also emplaced at roughly $56 \mathrm{Ma}$ [29]. The composition of the primary magma from unit 990-7 has been calculated [30] by back calculating along the crystallisation liquid lines of descent and is summarised in Table 1. From the crystallisation calculations used to generate the primary melt it was predicted that melting began at high temperatures $\left(1580\right.$ to $1460^{\circ} \mathrm{C}$ ) and there were high degrees of melting (15-21\%) [30]. The basalts sampled at site 918 were erupted when the rift had developed towards more steady rifting with more established magma reservoirs $[29,22]$.

\section{Methods}

\subsection{Melt depletion and Composition}

We have developed a model that first calculates the amount of melt generated during the rifting of continents and then predicts the primary composition of that melt. The modelling procedure can be broken down into two steps: First the mantle flow is calculated using a modified version of CitCom [31,11], which predicts the amount of melt generated during rifting (see Appendix A for a description of the model equations). The amount of melt generated is sensitive primarily to the spreading rate and mantle temperature. The second step uses the fraction of melt generated, the temperature and pressure within the melt region to calculate the melt major element composition. We have based these calculations on the two empirical parameterisations of Watson and McKenzie [32] and Niu [33] outlined below. Therefore there are three variables within 
this model: the initial mantle temperature structure, the spreading rate and the choice of composition parameterisation.

We have focused on two major element composition parameterisations:

1. The major element composition of accumulated melt was linked to fraction of melt generated and pressure by fitting polynomial functions to large data sets from batch melting experiments [1]. Additional corrections to the iron and magnesium oxides to maintain consistency with the olivine/liquid partition coefficient were made to this parameterisation by Watson and McKenzie, which we will refer to as WM91 [32]. The instantaneous melt composition, $C_{l}$, is found by the following empirical formula,

$$
C_{l}=a=b(1-F)^{\frac{1-D}{D}}
$$

where $F$ is the fraction of melt generated and $a, b$ and $D$ are estimated from a range of experimental data (see Appendix $\mathrm{C}$ within Watson and McKenzie $[32])$.

The statistical empirical approach of WM91 to generate a function for the composition of melt overestimates calcium oxide concentrations at low fractions of melting when the data is looked at qualitatively [34]. The bulk partition coefficient for sodium oxide is also grossly over estimated, leading Langmuir et al. [34] to suggest that the WM91 parameterisation is not much of an improvement upon more simplistic smoothed isobaric melting paths [20]. However WM91 is a robust quantitative parameterisation and can be used within melting models with relative ease due to the simple polynomial relationships that relate instantaneous melt composition to the fraction and pressure of melting.

2. An alternative approach to quantifying the composition of the melt is to use the partition coefficient, $D$, that determines the ratio of a particular oxide within the solid and liquid parts.

$D=\frac{C_{s}}{C_{l}}$ 
$C_{s}$ is the weight percent solid composition and $C_{l}$ is the liquid composition. By using the melting experiments of [35-37] and [38], Niu [33] calculates the apparent partition coefficients for the major elements as a function of temperature and degree of melting by constructing a mass balance, which we shall refer to as N97 [39,33]. Due to the lack of available data, N97 compositions at melt fractions less than $1 \%$ and at pressures greater than $2.5 \mathrm{GPa}$ are poorly constrained [33]. For fractions of melting less than $1 \%$ we calculate the partition coefficient assuming $1 \%$ melt and for pressures greater than $2.5 \mathrm{GPa}$ we similarly calculate the partition coefficients at $2.5 \mathrm{GPa}$.

For the N97 parameterisation the mantle source composition used is the MORB pyrolite of Falloon and Green [40]. WM91 uses empirical fits from laboratory melting experiments to derive a partitioning relation between melt composition and solid residue. Therefore both parameterisations assume a homogeneous source mantle composition. As such any variation of composition in the primary melts generated are only a result of spreading rate and temperature.

In order to calculate the composition of melt as the rift evolves we have incorporated the two major element composition parameterisations within the fully dynamic rifting model CitCom [31]. The melting calculations follow Nielsen and Hopper [11] using the parameterisation of Scott [8]. Melt fraction is predicted by tracing the concentration of a completely compatible element, $X$, through the melt region (see Appendix A). This conceptional quantity $X$ is always positive and equals one for fertile unmelted mantle and increases as melting progresses [8]. The composition of the solid, $C_{s}$ is given by (following from [41]),

$\frac{\partial C_{s}}{\partial t}+\mathbf{u} \cdot \nabla C_{S}=\left(1-\frac{1}{D}\right) \frac{C_{s}}{1-\phi} \dot{m}$

where $\mathbf{u}$ is the mantle flow, $\phi$ is the porosity and $\dot{m}$ is the melt production rate. For a completely compatible trace element, $D \rightarrow \infty$ :

$\frac{\partial X}{\partial t}+\mathbf{u} \cdot \nabla X=\frac{X}{1-\phi} \dot{m}$ 
We solve Equations 3 and 4 using a Petrov-Galerkin method for the advection [42] and then make a small perturbation to account for melting. Noting that during batch melting $X(1-F)=1$ [8] and that we account for the melting and advection of $X$ by Equation 4, WM91 and N97 can be implemented as both relate the major element composition of the melt to the fraction of melt generated. The notable difference between the two is that WM91 calculates melt composition solely from the total melting, where as N97 determines melt composition from the residue and a set of partition coefficients.

This difference in methods makes WM91 simpler to implement within the dynamic model as only Equation 4 must be solved. However N97 requires that at each time step Equation 3 and 4 are solved. This gives us the solid residue composition, and from the partition coefficient we calculate the instantaneous melt composition. Thus the composition of the residue is tracked as melting continues. Furthermore, as this method is based on partition coefficients it should be easily adaptable for other elements, such as rare earth elements that undergo very little fractionation during crystallisation.

Following Watson and McKenzie [32] the average composition of all the melt generated is given by the weighted average of the $C(F)$ over the melting region:

$\bar{C}=\frac{\iint_{\text {melt }} F C d x d z}{\iint_{\text {melt }} F d x d z}$

Thus assuming all melt is instantaneously removed at some depth from the centre of extension, the composition of the melt can be calculated for the evolution of the margin at different spreading rates and mantle potential temperatures. Likewise we calculate the bulk melt fraction, $F_{b u l k}$ as the integral,

$$
F_{b u l k}=\iint_{m e l t} F d x d z
$$

over the melt region. The igneous crustal thickness, $h_{c}$ is calculated assuming that all the melt is focused and accretes at the ridge axis following $[9,11]$,

$$
h_{c}=\frac{2}{u_{z}} \frac{\rho_{m}}{\rho_{l}} \iint_{m e l t} \dot{m} d x d z
$$


where $\rho_{m}$ is the mantle reference density and $\rho_{l}$ is the melt density (see Table 2 in Appendix A).

\subsection{Model boundary and initial conditions}

The top of the $2800 \mathrm{~km}$ wide by $700 \mathrm{~km}$ deep box (shown in Figure 2) is driven to the right at the chosen spreading velocity. We assume symmetry along the edge where the ridge develops and that there is no flow of heat or material across the boundary.

Nielsen and Hopper [11] modelled Atlantic opening with a constant spreading rate of $10 \mathrm{~mm} \mathrm{yr}^{-1}$. Here we initially make the same assumptions as Nielsen and Hopper, but also have a second condition where there is initially fast spreading of $40 \mathrm{~mm} \mathrm{yr}^{-1}$ for $4 \mathrm{Ma}$, followed by spreading at $10 \mathrm{~mm} \mathrm{yr}^{-1}$. The purpose of this latter model is to assess whether or not significant change in spreading rate during early breakup can affect melt production and chemistry. Geophysical data suggest that initial spreading rate was 3 to 4 times greater than the eventual slow spreading along the Reykjanes Ridge $[4,19]$.

The initial condition is as shown in Figure 2. Following Nielsen and Hopper [11], the continental lithosphere is pre-thinned with a half width of $\sim 25 \mathrm{~km}$ to control the onset of stretching. We tested the insertion of a hot layer $50 \mathrm{~km}$ thick with temperature increases of 100 and $200^{\circ} \mathrm{C}$. Models are set to hold a mantle potential temperature drop from the surface to the base of the model at $700 \mathrm{~km}$ depth. This value is set to between 1300 and $1325^{\circ} \mathrm{C}$ within the following sections. The effects of dehydration strengthening and melt weakening on the viscosity of the model are included (see [11] for details). Neither melt composition parameterisation accounts for the effects of wet melting on composition, so these are not included in our model. However since water is assumed to be removed by the time the melt fraction reaches $2 \%$ any errors will be small in predicted compositions. The Rayleigh number for the initial system (see Appendix A) is set to $1.091 \times 10^{5}$, to give a reference mantle viscosity of $4.5 \times 10^{20} \mathrm{Pas}[16]$. 


\section{Results and Discussion}

\subsection{Validation of Predicted Steady State Mid-Ocean Ridge Basalt}

The first step was to benchmark our model at steady state. To do so we have generated model runs from mantle potential temperatures of $1300^{\circ} \mathrm{C}$ to $1325^{\circ} \mathrm{C}$, and half spreading rates from $10 \mathrm{~mm} \mathrm{yr}^{-1}$ to $20 \mathrm{~mm} \mathrm{yr}^{-1}$ with no thermal anomaly beneath the lithosphere. This small range of spreading rates and mantle temperatures are tested as the steady state crustal thickness for such conditions is between 5 and $9 \mathrm{~km}$ which is representative of global midocean ridge thickness.

Melt generated at a steady state mid-ocean ridge is assumed to accumulate at the ridge axis where it begins to crystallise. The crystallisation depth depends on the thermal structure, and hence the spreading rate, of the ridge. Data from the mid Atlantic indicate crystallisation pressures of $\sim 200 \mathrm{MPa}$ [43]. To test the chemical predictions of the model, we calculate the melt chemistry produced at steady state and use Melts to predict the MORB compositions that would be produced assuming a crystallisation pressure of $200 \mathrm{MPa}$ [44,45]. We further assume a melt water composition of $0.2 \%$ and the fayalite-magnetitequartz redox reaction to calculate the ratio of $\mathrm{FeO}$ to $\mathrm{Fe}_{3} \mathrm{O}_{2}$. Liquid lines of descent are tracked until there is $8 \% \mathrm{MgO}$ to match the mean for North Atlantic MORB.

The WM91 parameterisation gives predicted MORB that lies within the range of observed North Atlantic MORB for all model runs (Figure 3(a)). The N97 parameterisation does not perform so well at steady state: aluminium and sodium oxide compositions are too high and calcium oxides too low (Figure 3(b)). The poorer performance of this parameterisation is not surprising as it is based on a smaller data set. Despite these problems, both parameterisations can predict North Atlantic MORB at steady state. 


\subsection{Primary Melts from Rifting at Constant Spreading Rates}

As just shown, the predicted melt composition at steady state gives a reasonable match to MORB. McKenzie et al [46] suggest that steady state oceanic mantle temperature is $1315^{\circ} \mathrm{C}$ and that a small increase in temperature of $12.5^{\circ} \mathrm{C}$ can increase crustal thickness by $1 \mathrm{~km}$. Within our model, as shown by Nielsen and Hopper [11], to generate a crustal thickness for a half spreading rate of $10 \mathrm{~mm} \mathrm{yr}^{-1}$ at steady state that is close to the 8 to $11 \mathrm{~km}$ crustal thickness of the Reykjanes Ridge [47-49] requires a slightly hotter mantle potential temperature of $1325^{\circ} \mathrm{C}$. Therefore within the following analysis of the evolution of the Southeast Greenland margin, we have assumed a mantle potential temperature of $1325^{\circ} \mathrm{C}$ and a half spreading rate of $10 \mathrm{~mm} \mathrm{yr}^{-1}$.

The lithospheric mantle is thought to have been between 100 and $200^{\circ} \mathrm{C}$ hotter than normal mantle when the North Atlantic opened (e.g. [13,30]). Given this idea and following [11], we have tested 100 and $200^{\circ} \mathrm{C}$ hot layers as initial conditions to represent a remnant plume head that has ponded under the lithosphere. Due to the hot layer, there is initially an elongated deep layer of low melt generation (less than 1\%, see Figure 4). Because of its buoyancy and low viscosity the hot layer is advected through the melt region (between 2 and $8 \mathrm{Myrs}$ of evolution) and the extent of melting rapidly increases, peaking at just below $30 \%$. Figure 4 also shows the instantaneous primary melt concentration of magnesium and silicon oxides for both parameterisations. We expect there to be a pressure dependance on the partitioning of iron, magnesium and silicon for both parameterisations. The deep melts should be dominated by those oxides that preferentially partition under high pressure, and this can be seen for iron and magnesium in both parameterisations (Figures 4, 5 and 6). It is likely however, that WM91 over estimates the concentration of silica at depth. This is possibly due to an underestimation of the other elements at depth, as silica concentration is calculated as $100 \%$ minus all the other oxides.

As the hot layer is advected through the melt region the melt generation increases significantly. The increased melt production is reflected in increased igneous crustal thickness and bulk melt fraction. With the addition of a $200^{\circ} \mathrm{C}$ hot layer the bulk melt fraction peaks at $15 \%$ and the igneous thickness peaks 
at $12 \mathrm{~km}$ during early rifting (Figure 5). The increased melt generation alters major element composition of the primary melt further. The two elements to consider closely are magnesium and sodium [13]. Magnesium oxides should become enriched within the melt with increasing melt depletion. Sodium oxides should deplete with increasing melt depletion [20]. The WM91 model reproduces this basic trend well: sodium and titanium oxides are incompatible and so partition into the early melt at low melt fractions. As the melt production increases these elements take up a smaller fraction of the melt as the other more compatible oxides: magnesium, silicon and iron partition into the melt (Figure 5). Furthermore the WM91 parameterisation predicts the exhaustion of clinopyroxene within the regions of high melt production (melt fractions $>20 \%$ ) as predicted from melting of a fertile mantle peridotite by Herzberg and O'Hara [50]. This causes the peak in the ratio of aluminium to calcium seen during early evolution (Figure 5).

The high melt fractions have quite a different effect on the primary melt composition according to the N97 parameterisation (see Figure 6). Magnesium oxide trends are not close to what would be expected. The parameterisation fails to reproduce a significant increase in magnesium oxides that is matched with any increase in iron oxides during periods of high melt production. Sodium oxides do show a depletion as melt production increases. The calcium aluminium ratio and silicon oxide composition show an evolution that fits well with the arguments presented: an increase in the ratio when melt fractions are high. Silicon oxide composition begins low and increases with melt production as is expected [20]. Finally for titanium the N97 parameterisation is in very close agreement with WM91.

The N97 model gives reasonable trends for calcium, aluminium, titanium and silicon oxide concentrations, however as a first order tool for calculating primary melt compositions, magnesium and sodium oxide trends must match reasoned geochemical arguments. It would appear that WM91 performs better than N97 from the sodium and magnesium oxide trends with melt production. A likely reason for this is that N97 miss-represents high pressure and low fraction melt due to a lack of supporting data. 
We compare results from the both models with the estimated primary melt composition during early breakup of the Southeast Greenland margin from ODP sites 917 and 990 ([51,27,30], Figures 5 and 6). We match the time of peak melt production in the model to the maximum igneous thickness measured by Holbrook et al. [12]. The site 917 and 990 basalts were likely erupted during the final stages of breakup at $56 \mathrm{Ma}$ [25,22]. Given these observations we have plotted the estimated primary compositions from ODP sites 917 and 990 (see Table 1) at $56 \mathrm{Ma}$, which matches peak production.

For all oxides except calcium and aluminium, the WM91 model with the inclusion of a hot layer predicts a composition that is in closer agreement than a model without the hot layer, although the maximum igneous thickness is underpredicted (see Figure 5). The result from the N97 model is perhaps in better agreement with predicted primary melt for the calcium aluminium ratio and silicon oxide, but for iron, and more importantly magnesium, the parameterisation gives results that are quite inaccurate. Given these inaccuracies and the poorer agreement of the N97 model with North Atlantic MORB at steady state, we conclude that the WM91 parameterisation is more suitable for modelling the South East Greenland margin.

\subsection{Prediction of Southeast Greenland Basalt Compositions}

ODP leg 152 site 918 sampled mildly altered basalts from the seaward dipping reflector series (SDRS) off Southeast Greenland [51,4]. Site 918 also penetrated a younger iron and titanium oxide rich sill, possibly emplaced by an off axis volcano $[51,19]$. The basalt from the SDRS is dated at $54 \mathrm{Ma}[29]$ therefore it was emplaced soon after sea floor spreading had begun. Here we do not wish to get into a debate on the crystallisation processes that take place within the evolving Southeast Greenland margin. We are however aware that it would be ideal to validate our model results against further rock samples. Rather than attempt to predict primary melts from the observed compositions, we have used the script driven front end to Melts: Adiabat_1ph [52], to crystallise our predicted primary composition for this site. 
As mentioned earlier, Atlantic MORB crystallises at pressures of around $200 \mathrm{MPa}$ [43]. Assuming isobaric batch crystallisation within pooled melt at that pressure, liquid lines of descent for crystallisation of primary melts generated during breakup are plotted in Figure 7. We have then taken a comparison of our simple liquid lines of descent with the composition of the SDRS sampled at ODP site 918. We find that the low titanium, high magnesium primary melt, when crystallised, can account for the titanium magnesium ratio seen in the SDRS. Furthermore when younger steady state primary melt is crystallised we generate basalts with a titanium magnesium ratio representative of the sill basalt.

Our crystallisation has been less successful at predicting other major element ratios, although it is not far off for some elements such as silicon and iron oxides (see Figure 7). This is likely due to the liquid line of descent being more complicated than the simple isobaric approach taken here. Given that the primary melts we generate are picritic and are generated at depths of up to $100 \mathrm{~km}$, there may be some significant crystallisation en route to magma pools and/or fractures. There will also be mixing and crystallisation within magma pools, and further crystallisation and interaction with rock upon eruption. Given all the possible scenarios we find it encouraging that we can generate major element compositions close to the basalts erupted soon after breakup.

\subsection{Primary Melts from Rifting at Variable Spreading Rates}

Sea floor spreading rates are not constant. When the Southeast Greenland margin opened it did so at a faster spreading rate of around $\sim 40 \mathrm{~mm} \mathrm{yr}^{-1}$ for approximately $4 \mathrm{Myr}$ and then spreading settled to its current rate of around $10 \mathrm{~mm} \mathrm{yr}^{-1}$. This simplification of the extension history of the opening of the margin is based on two sources. From the SIGMA III survey if we assume that the continent-ocean boundary (COB) forms at $56 \mathrm{Ma}$ and everything farther west is erupted on continental crust, from the COB to Anomaly C24n is a little more than $100 \mathrm{~km}$ or about $33 \mathrm{~mm} \mathrm{yr}^{-1}$ on average [4]. Larsen and Saunders [25] suggest a slightly higher $44 \mathrm{~mm} \mathrm{yr}^{-1}$ peak half spreading rate that abates to $11 \mathrm{~mm} \mathrm{yr}^{-1}$ based on the interpretation of magnetic anomalies 
and argon-argon ages [23,26].

Using the WM91 parameterisation we have modelled the rifting of the Southeast Greenland margin using a step change in spreading rate. It can be clearly seen that if we introduce a sublithospheric hot layer of $200^{\circ} \mathrm{C}$ then the crustal thickness measured by [12] can be recreated with a high degree of accuracy if we match peak volume with the opening of the rift. Equally, the duration, $\sim 1$ Myrs, of peak melt production matches very closely the duration of peak magma productivity estimated from Greenland - Faeroes lavas [53]. Previous models have attempted to explain thick igneous crusts by purely thermal anomalies (e.g. [13,10,11], Figure 5); we find that in order to recreate the crustal thickness off South East Greenland initial fast spreading is required in addition to a thermal anomaly.

From Figure 8, composition variations may be better predicted by a slightly cooler hot layer than is required to generate the igneous crustal thickness. A $100^{\circ} \mathrm{C}$ hot layer predicts primary MORB compositions that are close for all major elements with the exception of the calcium aluminium ratio and the silica concentration. Inclusion of a $200^{\circ} \mathrm{C}$ hot layer tends to over-predict the magnesium concentration of primary melt with a very high peak in magnesium oxides. The increased spreading rate during early rifting causes increased upwelling and so even greater melting rates than when the spreading is only $10 \mathrm{~mm} \mathrm{yr}^{-1}$. Thus the trends seen in Figure 5 are exaggerated as there is more melt present, with the bulk melt fraction exceeding $25 \%$.

Even if the major element composition is not completely recreated, as clearly the case for silicon oxide concentrations (Figure 8), we have recreated a strong geochemical signature within the primary melt that following crystallisation can generate compositions like that of Southeast Greenland MORB (Figure 7). It is generally believed that the mantle material that generated the North Atlantic igneous province can be traced back to an Iceland plume signature, e.g. [55]. We have shown in this section, and even for when there is no variation in spreading rate, that no anomalous mantle source composition is required to generate the anomalous major element composition of the primary melt. The generation of thick igneous crust upon breakup requires a thermal anomaly, 
but a layer of hotter mantle without a deep root will suffice under the right conditions. The rapid reduction in crustal thickness after breakup is well modelled by a finite reservoir of high temperature mantle. Such a model is consistent with active upwelling and lateral channelling of hot asthenosphere along the Southeast Greenland margin during breakup [11,12,16,54].

\section{Conclusions}

Within this study we set out to study two variables within the rift evolution of the Southeast Greenland margin: firstly, the effect that initial temperature structure has on melt production and melt composition; and secondly, the effect of initial spreading rates on melt production and composition. In doing so we have produced a robust model that can generate North Atlantic MORB at steady state and match the igneous thickness of the Reykjanes Ridge, whilst generating a pulse of picritic, thick igneous crust during early rifting.

To generate the major element composition of primary melts that closely match the expected composition of primary melts in the distal field of the possible Iceland plume at the Southeast Greenland margin (ODP sites 917,918 and 990) has not required a compositional Iceland plume source signature. Rather we find a that the presence of an exhaustible sublithospheric hot layer during continental breakup can account for the region of thickened crust off shore Southeast Greenland. Importantly, when coupled with a pulse of fast extension, such a layer can also account for the observed picritic composition of primary melts.

Our analysis does not address the origin of such a hot layer, however its presence is consistent the lateral movement of a thermal plume based under Iceland [12]. This thermal anomaly migrated south prior to the breakup of the North Atlantic, giving the observed volumes and picritic compositions of the oceanic crust off Southeast Greenland. 


\section{Acknowledgements}

We are grateful to Simon Dean for the use of his melt parameterisation code. We would also like to thank David Sparks, Charles Lesher and Bramley Murton for constructive and enjoyable discussions regarding all aspects of this paper. This project was supported by the NERC Oceans Margins LINK thematic program through a studentship for John Armitage. We would also like to thank Claude Jaupart and an anonamous reviewer for their constructive comments.

\section{Appendix A - Model Equations}

We have used the combined Stokes and energy equation solver, CitCom, for incompressible flow over large viscosity contrasts (see [11,31]). Here we will briefly go through the model equations, which are explained further within references $[8,11]$ and [31]. The base equations are the conservation of mass, momentum and energy. We will use the following summation convention: as an example we have expanded the divergence of the mantle flow,

$$
\nabla \cdot \mathbf{u}=\frac{\partial u_{1}}{\partial x_{1}}+\frac{\partial u_{2}}{\partial x_{2}}
$$

where $\mathbf{u}$ is the mantle flow vector, $u_{1}$ and $x_{1}$ are the mantle flow and displacement in the horizontal $x$-direction and $u_{2}$ and $x_{2}$ are the flow and displacement in the vertical $z$-direction. Equation 8 can be rewritten as,

$\nabla \cdot \mathbf{u}=\sum_{i=1}^{2} \frac{\partial u_{i}}{\partial x_{i}}$

and then by leaving out the summation sign, $\sum$, with the understanding that repeated indices are summed, the conservation of mass, momentum and energy can be written as,

${ }_{423} \quad \frac{\partial u_{i}}{\partial x_{i}}=0$ 
$-\frac{\partial \tau_{i j}}{\partial x_{j}}+\frac{\partial p}{\partial x_{i}}=\Delta \rho \lambda_{i}$

$$
\frac{\partial T}{\partial t}=-u_{i} \frac{\partial T}{\partial x_{i}}+\kappa \frac{\partial^{2} T}{\partial x_{j}^{2}}-\frac{L \dot{m}}{c_{p}}
$$

where $u$ is the solid mantle creep, $T$ is the mantle temperature, $\tau$ is the deviatoric stress tensor, $\Delta \rho$ is the density change due to temperature and the generation of melt, $\dot{m}$ is the melt production rate and $\lambda_{i}$ is a unit vector in the vertical direction (i.e. $\lambda_{1}=0, \lambda_{2}=1$ ). The other constants are defined within Table 2.

\section{Stress and Rheology}

Deviatoric stress is given by,

$$
\tau_{i j}=2 \eta \epsilon_{i j}
$$

where $\epsilon_{i j}$ is the strain rate and $\eta$ is the viscosity given by the following rheological definition,

$$
\eta=A \chi_{H_{2} O} \chi_{m} \exp \left(\frac{E+p V}{n R T}\right) \dot{\epsilon}^{\frac{1-n}{n}}
$$

where $E$ is the activation energy, $V$ is the activation volume, $n$ is the stress exponent and $R$ is the gas constant. $A$ is a rheological parameter set from the reference state of $T=1598 \mathrm{~K}, \eta=4.5 \times 10^{20} \mathrm{Pas}$ and $\dot{\epsilon}=1 \times 10^{-15} \mathrm{~s}^{-1}$. The rheological definition has two further terms to account for the strengthening of the mantle due to the removal of mantle volatiles $\chi_{\mathrm{H}_{2} \mathrm{O}}$, and the weakening of the mantle due to small amounts of melt, melt weakening, $\chi_{m}$. Following [11] the strengthening factor varies linearly from 0 to 10 as melting progresses up till $2 \%$ of melt is generated. The mantle is then assumed to be completely depleted of mantle volatiles and the strengthening factor increases to 100. The melt weakening term is given as (from [57]),

$$
\chi_{m}=\exp (-45 \phi)
$$


The change in density of the mantle due to temperature and melting is given by,

$$
\Delta \rho=-\rho_{0}(\alpha T+\gamma \phi+\beta F)
$$

where $\alpha$ is the coefficient of thermal expansion. $\gamma$ and $\beta$ are constant to scale the melt porosity, $\phi$, and melt fraction, $F$, terms and shall be defined later. Melt porosity is the volume occupied within the mantle by melt and is governed by advection and compaction [8],

$\frac{\partial \phi}{\partial t}+u_{i} \frac{\partial \phi}{\partial x_{i}}-(1-\phi) \frac{\partial u_{j}}{\partial x_{j}}=\dot{m}$

The fraction of melt generated, $F$, is calculated from the advection of the melting residue, $X$, of a completely compatible trace element (as Equation 4 in tensor notation),

${ }_{460} \quad \frac{\partial X}{\partial t}+u_{i} \frac{\partial X}{\partial x_{i}}=\frac{X}{1-\phi} \dot{m}$

Assuming batch melting during each time step then the melt fraction can be estimated from (from [8]),

$$
X(1-F)=1
$$

Therefore Equations 17 and 18, combined with the relationship above (Equation 19), can be used to calculate the buoyant addition to the upwelling due to the presence of melt using Equation 16. Where $\gamma$ is given by,

${ }_{467} \quad \gamma=\frac{\rho_{m}-\rho_{l}}{\rho_{m}}$

and $\beta$ is given by,

${ }_{469} \quad \beta=\frac{\rho_{m}-\rho_{r}}{\rho_{m}\left(X_{r}-1\right)}$ 
482

and the constants are listed in Table 2.

Equations 12, 17 and 18 are linked by the rate of melt production $\dot{m}$. The melt production rate is calculated at each time step by calculating the position of the wet and dry solidus as described within [11]. The amount of melt produced at that time step is then given by,

$$
\delta m=\frac{\delta t}{\frac{L}{c_{p}}+\frac{\partial T_{s}}{\partial \phi}}
$$

where $\delta T=T-T_{s}$ and $T_{s}$ is the wet or dry solidus temperature. The latent heat capacity, $L=T_{s} \Delta S$, where $\Delta S$ is the entropy change due to melting and $c_{p}$ is the specific heat capacity. The differential $\partial T_{s} / \partial \phi$ is given by, when in the wet melting regime (from [58]),

$\frac{\partial T_{s}}{\partial \phi}=1440 \frac{X}{1-\phi}$

and when in the dry melting regime,

$\frac{\partial T_{s}}{\partial \phi}=440 \frac{X}{1-\phi}$

Therefore the melt production rate is simply,

$\dot{m}=\frac{\delta m}{\delta t}$

where $\delta t$ is the advection time step.

\section{Dimensions}

The main equations of flow (Equations 10, 11 and 12) are made non-dimensional in the following manner,

$\quad x=d x^{\prime}, \quad t=\frac{d^{2}}{\kappa} t^{\prime}, \quad T=\Delta T T^{\prime}, \quad \eta=\eta_{0} \eta^{\prime}$

where, as in Nielsen and Hopper [11], $d$ is the depth of the model space, $\eta_{0}$ is the viscosity at the base of the model space and $\Delta T$ is the super-adiabatic 
494

496

temperature drop from the base of the model space to the surface. Therefore the buoyancy term (Equation 16) becomes,

$$
\Delta \rho=\frac{\rho_{0} g d^{3}}{\kappa \eta_{0}}(\alpha \Delta T T+\gamma \phi+\beta F)
$$

Furthermore, we define a thermal Rayleigh number,

$$
R a=\frac{\rho_{0} g \alpha \Delta T d^{3}}{\kappa \eta_{0}}
$$

which as mentioned in the main text we set to $1.091 \times 10^{5}$, to give a reference mantle viscosity, $\eta_{0}$, of $4.5 \times 10^{20} \mathrm{Pas}$

\section{References}

[1] D. P. McKenzie, M. J. Bickle, The volume and composition of melt generated by extension of the lithosphere, Journal of Petrology 29 (1988) 625-679.

[2] S. R. Fowler, R. S. White, G. D. Spence, G. K. Westbrook, The Hatton Bank continental margin - II. Deep structure for two-ship expanding spread seismic profiles, Geophysical Journal International 96 (1989) 295-309.

[3] P. F. Barton, R. S. White, Crustal structure of the Edoras Bank margin and mantle thermal anomalies beneath the North Atlantic, Journal of Geophysical Research 103 (1997) 3109-3129.

[4] J. R. Hopper, T. Dahl-Jensen, W. S. Holbrook, H. C. Larsen, D. Lizarradle, J. Korenaga, G. M. Kent, P. B. Kelemen, Structure of the SE Greenland margin from seismic reflection and refraction data: Implications for nascent spreading centre subsidence and asymmetric crustal accretion during North Atlantic opening, Journal of Geophysical Research 108 (2003) doi: 10.1029/2002JB001996.

[5] J. W. Bown, R. S. White, Variation with spreading rate of oceanic crust thickness and geochemistry, Earth and Planetary Science Letters 121 (1994) $435-449$. 
[6] J. W. Bown, R. S. White, Effect of finite extension rate on melt generation at rifted continental margins, Journal of Geophysical Research 100 (1995) 1801118029.

[7] M. Williamson, R. C. Courtney, C. E. Keen, S. A. Dehler, The volume and rare Earth concentrations of magmas generated during finite stretching of the lithosphere, Journal of Petrology 36 (1995) 1433-1453.

[8] D. R. Scott, Small-scale convection and mantle melting beneath mid-ocean ridges, in: Mantle flow and melt generation at mid-ocean ridges, Vol. Geophysical Monograph 71, American Geophysical Union, 1992, pp. 327-352.

[9] G. Ito, J. Lin, C. W. Gable, Dynamics of mantle flow and melting at ridgecentred hotspot: Iceland and the Mid-Atlantic Ridge, Earth and Planetary Science Letters 144 (1996) 53-74.

[10] R. P. Boutilier, C. E. Keen, Small-scale convection and divergent plate boundaries, Journal of Geophysical Research 104 (1999) 7389-7403.

[11] T. K. Nielsen, J. R. Hopper, From rift to drift: mantle melting during continental breakup, Geochemistry Geophysics Geosystems 5 (2004) doi: 10.1029/2003GC000662.

[12] W. S. Holbrook, H. C. Larsen, J. Korenaga, T. Dahl-Jensen, I. D. Reid, P. B. Kelemen, J. R. Hopper, G. M. Kent, D. Lizarradle, S. Bernstein, R. S. Detrick, Mantle thermal structure and active upwelling during continental breakup in the north Atlantic, Earth and Planetary Science Letters 190 (2001) 251-266.

[13] R. S. White, D. P. McKenzie, Magmatism at rift zones: the generation of volcanic continental margins and flood basalts, Journal of Geophysical Research 94 (1989) 7685-7729.

[14] M. Storey, R. A. Duncan , A. K. Pedersen, L. M. Larsen, H. C. Larsen, ${ }^{40} \mathrm{Ar} /{ }^{39} \mathrm{Ar}$ geochronology of the West Greenland Tertiary volcanic province, Earth and Planetary Science Letters 160 (1998) 569-586.

[15] M. Storey, R. A. Duncan, C. Tegner, Timing and duration of volcanism in the North Atlanic Igneous Province: Implications for geodynamics and links to the Iceland hotspot, Chemical Geology, 241 (2007) 264-281.

[16] T. K. Nielsen, J. R. Hopper, Formation of volcanic rifted margins: are temperature anomalies required?, Geophysical Research Letters 29 (2002) doi: 10.1029/2002GL015681. 
[17] S. C. Cande, D. V. Kent, Revised calibration of the geomagnetic polarity timescale for the Late Cretaceous and Cenozoic, Journal of Geophysical Research 100 (1995) 6093-6095.

[18] W. A. Berggren, D. V. Kent, C. C. Swisher III, M.-P. Audry, A revised Cenzoic geometry and chronostratigraphy, in: W. A. Berggren, D. V. Kent, M.-P. Audry, J. Hardenbol (Eds.), Geochronology, Time Scales and Global Stratigraphic Correlation, Vol. SEPM special publication, 54, SEPM, 1995, pp. 129-212.

[19] L. M. Larsen, J. G. Fitton, M. S. Fram, Volcanic rocks of the southeast Greanland margin in comparison with other parts of the north Atlanic tertiary igneous province, Proceedings of the Ocean Drilling Program, Scientific Results 152 (1998) 315-330.

[20] E. M. Klein, C. H. Langmuir, Global correlations of ocean ridge basalt chemistry with axial depth and crustal thickness, Journal of geophysical research 92 (1987) 8089-8115.

[21] M. S. Fram, C. E. Lesher, A. M. Volpe, Mantle melting systematics: transition from continental to oceanic volcanism on the Southeast Greenland margin, Proceedings of the Ocean Drilling Program, Scientific Results 152 (1998) 373386.

[22] J. G. Fitton, L. M. Larsen, A. D. Saunders, B. S. Hardarson, P. D. Kempton, Palaeogene continental to oceanic magmatism on the SE Greenland continental margin at $63^{\circ} \mathrm{N}$ : a review of the results of ocean drilling program legs 152 and 163, Journal of Petrology 41 (2000) 951-966.

[23] H. C. Larsen, H. C. Saunders, P. D. Clift, et al (Eds.), Proceedings of the Ocean Drilling Program, Scientific Results, 152, Ocean Drilling Program, College Station, TX, 1994.

[24] J. G. Fitton, A. D. Saunders, L. M. Larsen, M. S. Fram, A. Demant, C. Sinton, Leg 152 Shipboard Scientific Party, Magma sources and plumbing systems during break-up of the SE Greenland margin: preliminary results from ODP leg 152, Journal of the Geological Society, London 152 (1995) 985-990.

[25] H. Larsen, A. Saunders, Tectonism and volcanism at the southeast Greenland rifted margin: A record of plume impact and later continental rupture, Proceedings of the Ocean Drilling Program, Scientific Results 152 (1998) 503533. 
[26] C. W. Sinton, R. A. Duncan, ${ }^{40}$ Ar- ${ }^{39}$ ages of lavas from the southeast Greenland margin, ODP leg 152, and the Rockhall plateau, DSDP 81, Proceedings of the Ocean Drilling Program, Scientific Results 152 (1998) 387-402.

[27] P. Thy, C. E. Lesher, M. S. Fram, Low pressure experimental constraints on the evolution of basaltic lavas from site 917, southeast Greenland continental margin, Proceedings of the Ocean Drilling Program, Scientific Results 152 (1998) 359-372.

[28] E. G. Nisbet, M. J. Cheadle, N. T. Arndt, M. J. Bickle, Constraining the potential temperature of the Archaean mantle: a review of the evidence from komaliites, Lithos 30 (1993) 291-308.

[29] C. Tegner, R. A. Duncan, ${ }^{40}$ Ar- ${ }^{39}$ chronology for the volcanic history of the southeast Greenland rifted margin, Proceedings of the Ocean Drilling Program, Scientific Results 163 (1999) 53-63.

[30] L. M. Larsen, J. G. Fitton, A. D. Saunders, Composition of volcanic rocks from the Southeast Greenland margin, leg 163: major and trace element geochemistry, Proceedings of the Ocean Drilling Program, Scientific Results 163 (1999) 63-75.

[31] L. Moresi, V. S. Solomatov, Numerical investigation of 2D convection with extremely large viscosity variations, Physics of Fluids 7 (1995) 2154-2162.

[32] S. Watson, D. McKenzie, Melt generation by plumes: a study of Hawiian volcanism, Journal of Petrology 32 (1991) 501-537.

[33] Y. Niu, Mantle melting and melt extraction processes beneath ocean ridges: Evidence from abyssal peridotites, Journal of Petrology 38 (1997) 1047-1074.

[34] H. H. Langmuir, E. M. Klein, T. Plank, Petrological systematics of mid-ocean ridge basalts: constraints on melt generation beneath ocean ridges, in: Mantle flow and melt generation at mid-ocean ridges, Vol. Geophysical Monograph 71, American Geophysical Union, 1992, pp. 183-280.

[35] A. L. Jaques, D. H. Green, Anhydrous melting of peridotite at 0-15kb pressure and the genisis of tholeiitic basalts, Contributions to Mineralogy and Petrology 73 (1980) 287-310.

[36] T. J. Falloon, D. H. Green, C. J. Hatton, K. L. Harris, Anhydrous partial melting of a fertile and depleted peridotite from 2 to $30 \mathrm{~kb}$ and application to basalt petrogenesis, Journal of Petrology 29 (1988) 1257-1282. 
[37] K. Hirose, I. Kushiro, Partial melting of dry peridiotites at high pressures: determination of compositions of melt segregated from peridiotite using aggregates of diamonds, Earth Planetary Science Letters 114 (1993) 477-489.

[38] M. B. Baker, E. M. Stopler, Determining the composition of high-pressure mantle melts using diamond aggregates, Geochimica et Cosmochimica Acta 58 (1994) 2811-2827.

[39] Y. Niu, R. Batiza, An empirical method for calculating melt compositions produced beneath mid-ocean ridges: application for axis and off-axis (seamounts) melting, Journal of Geophysical Research 96 (B13) (1991) 2175321777.

[40] T. J. Falloon, D. H. Green, Anhydrous partial melting of MORB pyrolite and other peridotite compositions at 10kbar: Implications for the origin of MORB glasses, Mineralogy and Petrology 37 (1987) 181-219.

[41] M. Spiegelman, Geochemical consequences of melt transport in 2-D: The sensitivity of trace elements to mantle dynamics, Earth and Planetary Science Letters 139 (1996) 115-132.

[42] A. N. Brooks, T. J. R. Hughes, Streamline upwind/Petrov-Galerkin formulations for convection dominated flows with particular emphasis on the incompressible Navier-Stokes equations, Computer Methods in Applied Mechanics and Engineering 32 (1982) 199-259.

[43] C. Herzberg, Partial crystallisation of mid-ocean ridge basalts in the crust and mantle, Journal of Petrology 45 (2004) 2389-2405, doi: 10.1093/petrology/egh040.

[44] M. S. Ghiorso, R. O. Sack, Chemical mass-transfer in magmatic processes IV. A revised and internally consistent thermodynamic model for the interpolation and extrapolation of liquid-solid equilibria in magnetic systems at elevated temperatures and pressures, Contributions to Mineralogy and Petrology 119 (1995) 197-212.

[45] P. D. Asimow, M. S. Ghiorso, Algorithmic modifications extending MELTS to calculate subsolidus phase relations, American Mineralogist 83 (1998) 11271132 .

[46] D. McKenzie, J. Jackson, K. Priestley, Thermal structure of oceanic and 
continental lithosphere, Earth and Planetary Science Letters 233 (2005) 337349 .

[47] J. R. Smallwood, R. S. White, Crustal accretion at the Reykjanes Ridge, 61 degrees - 62 degrees n, Journal of Geophysical Research 103 (1998) 5185-5201.

[48] N. R. Weir, R. S. White, B. Brandisdóttir, P. Einarsson, H. Shimamura, H. Shiobara, the RISE Fieldwork Team, Crustal structure of the northern Reykjanes Ridge and Reykjanes Peninsula, southwest Iceland, Journal of Geophysical Research 106 (2001) 6347-6368.

[49] W. R. Jacoby, W. Weigel, T. Fedorova, Crustal structure of the Reykjanes Ridge near $62^{\circ} \mathrm{n}$, on the basis of seismic refraction and gravity data, Journal of Geodynamics 43 (2007) 55-72.

[50] C. Herzberg, M. J. O'Hara, Plume-associated ultramafic magmas of phanerzoic age, Journal of Petrology 43 (2002) 1857-1883.

[51] J. G. Fitton, A. D. Saunders, L. M. Larsen, B. S. Hardarson, M. J. Norry, Volcanic rocks from the southeast Greenland margin at $63^{\circ} \mathrm{N}$ : composition, petrogenisis, and mantle sources, Proceedings of the Ocean Drilling Program, Scientific Results 152 (1998) 331-350.

[52] P. M. Smith, P. D. Asimow, Adiabat 1ph: a new public front-end to the MELTS, pMELTS and pHMELTS models, Geochemistry Geophysics Geosystems 6 (2005) doi:10.1029/2004GC000816.

[53] M. Storey, R. A. Duncan, C. C. Swisher III, Paleocene-Eocene thermal maximum and opening of the Northeaast Atlantic, Science 316 (2007) 587-589, doi: 10.1126/science.1135274.

[54] C. Tegner, C. E. Lesher, L. M. Larsen, W. S. Watt, Evidence from the rareearth-element record of mantle melting for cooling of the Tertiary Iceland plume, Nature 395 (1998) 591-594.

[55] J. G. Fitton, A. D. Saunders, M. J. Norry, B. S. Hardson, R. N. Taylor, Thermal and chemical structure of the Iceland plume, Earth and Planetary Science Letters 153 (1997) 197-208.

[56] T. K. Nielsen, H. C. Larsen, J. R. Hopper, Constraining rifting margin styles south of Greenland: implications for mantle plume dynamics, Earth and Planetary Science Letters 200 (2002) 271-286. 
[57] P. B. Kelemen, G. Hirth, N. Shimizu, M. Spiegelman, H. J. B. Dick, A review of melt migration processes in the adiabatically upwelling mantle beneath oceanic spreading ridges, Philosophical Transactions of the Royal Society London A 355 (1997) 283-318.

[58] M. G. Braun, G. Hirth, E. M. Parmentier, The effects of deep damp melting on mantle flow and melt generation beneath mid-ocean ridges, Earth and Planetary Science Letters 176 (2000) 339-356.

[59] J. Verhoef, W. R. Roest, R. Macnab, Members of the Project Team, Arctic and North Atlantic Oceans and adjacent land areas, magnetic anomalies, geological Survey of Canada, Ottawa, Open File 3125a (1996). 
Table 1

Measured and calculate primary melt compositions from ODP leg 152, site 917 and ODP leg 163, site 990

\begin{tabular}{|c|c|c|c|c|c|c|c|c|}
\hline Site - unit & $\mathrm{SiO}_{2}$ & $\mathrm{TiO}$ & $\mathrm{Al}_{2} \mathrm{O}_{3}$ & $\mathrm{FeO}$ & $\mathrm{MgO}$ & $\mathrm{CaO}$ & $\mathrm{Na}_{2} \mathrm{O}$ & $\mathrm{K}_{2} \mathrm{O}$ \\
\hline $917-14$ & 46.77 & 0.72 & 14.30 & 10.65 & 17.67 & 7.86 & 1.61 & 0.06 \\
\hline $917-16$ & 47.38 & 0.91 & 13.09 & 11.09 & 17.80 & 7.31 & 1.78 & 0.23 \\
\hline \multicolumn{9}{|l|}{ Calculated } \\
\hline $917-11 R 4$ & 46.88 & 0.96 & 12.40 & 11.00 & 17.76 & 8.71 & 1.67 & 0.17 \\
\hline $917-17$ & 47.81 & 0.90 & 13.93 & 9.68 & 15.31 & 9.52 & 2.12 & 0.31 \\
\hline $990-7$ & 48.45 & 0.71 & 10.89 & 11.21 & 18.01 & 8.88 & 1.54 & 0.08 \\
\hline
\end{tabular}

Units 917-14 and 917-16 from Larsen et al. [19], 11R4 and 917-17 are estimated by Thy et al. [27]; unit 990-7 primary composition was estimated by Larsen at al. [30].

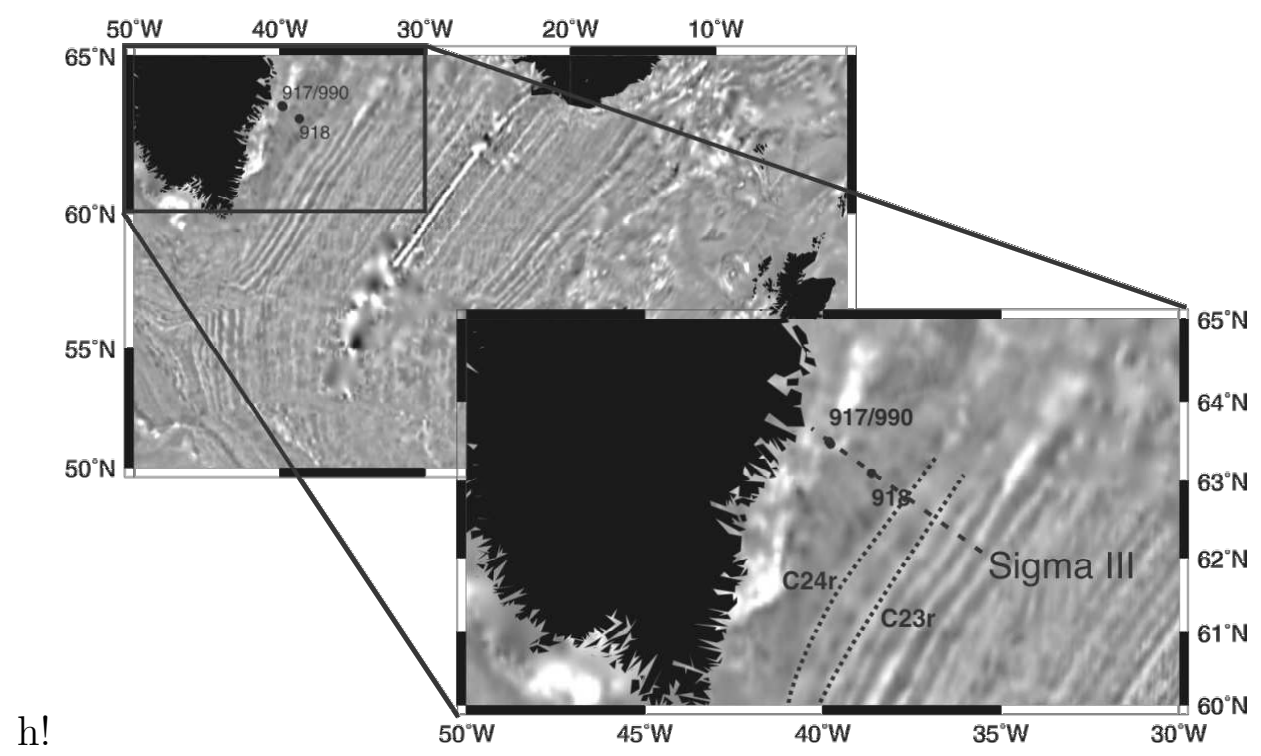

Fig. 1. The North Atlantic, ODP sites 917,918 and 990 are marked off Southeast Greenland. Inset shows approximate locations of magnetic chrons C24r and C23r and the Sigma III survey line. Shading shows magnetic anomalies [59]. 
Table 2

Model parameters and assumed values

\begin{tabular}{|c|c|c|}
\hline Variable & Meaning and Units & Value \\
\hline$c_{p}$ & specific heat capacity, $\mathrm{J} \mathrm{kg}^{-1} \mathrm{~K}^{-1}$ & 1200 \\
\hline$d$ & depth of model space, $\mathrm{km}$ & 700 \\
\hline$g$ & acceleration of gravity, $\mathrm{m} \mathrm{s}^{-2}$ & 9.8 \\
\hline$E$ & activation energy, $\mathrm{J} \mathrm{mol}^{-1}$ & $530 \times 10^{3}$ \\
\hline$\dot{m}$ & dimensionless melt production rate & \\
\hline$n$ & stress exponent & 3 \\
\hline$p$ & pressure, $\mathrm{Pa}$ & \\
\hline$R$ & gas constant, $\mathrm{J} \mathrm{K}^{-1} \mathrm{~mol}^{-1}$ & 8.314 \\
\hline$\Delta S$ & Change in entropy upon melting & 250 \\
\hline$T$ & mantle temperature, $\mathrm{K}$ & \\
\hline$\Delta T$ & super adiabatic temperature drop, $\mathrm{K}$ & 1325 \\
\hline$T_{s}$ & wet or dry solidus temperature, $\mathrm{K}$ & \\
\hline$u$ & mantle creep, $\mathrm{ms}^{-1}$ & \\
\hline$V$ & activation volume, $\mathrm{m}^{3} \mathrm{~mol}^{-1} 5 \times 10^{-6}$ & \\
\hline$X$ & concentration of perfectly compatible trace element & \\
\hline$X_{r}$ & reference concentration of a perfectly compatible trace element & 1.3 \\
\hline$\alpha$ & coefficient of thermal expansion, $\mathrm{K}^{-1}$ & $3.3 \times 10^{-1}$ \\
\hline$\beta$ & coefficient of depletion density reduction & 0.04 \\
\hline$\dot{\epsilon}$ & strain rate, $\mathrm{s}^{-1}$ & \\
\hline$\gamma$ & coefficient of melt density reduction & 0.16 \\
\hline$\kappa$ & thermal diffusivity, $\mathrm{m}^{2} \mathrm{~s}^{-1}$ & $10^{-6}$ \\
\hline$\eta$ & viscosity, $\mathrm{Pas}$ & \\
\hline$\eta_{0}$ & reference viscosity at base of model, Pas & \\
\hline$\phi$ & retained melt (porosity) & \\
\hline$\rho_{m}$ & mantle reference density, $\mathrm{kg} \mathrm{m}^{-3}$ & 3340 \\
\hline$\rho_{l}$ & melt density, $\mathrm{kg} \mathrm{m}^{-3}$ & 2800 \\
\hline$\rho_{r}$ & density of mantle at reference residue $X_{r}, \mathrm{~kg} \mathrm{~m}^{-3}$ & 3295 \\
\hline$\tau$ & deviatoric stress, $\mathrm{Pa}$ & \\
\hline$\chi_{\mathrm{H}_{2} \mathrm{O}}$ & viscosity increase factor due to dehydration & $0-100$ \\
\hline$\chi_{m}$ & viscosity reduction factor due to interstitial melt & \\
\hline
\end{tabular}




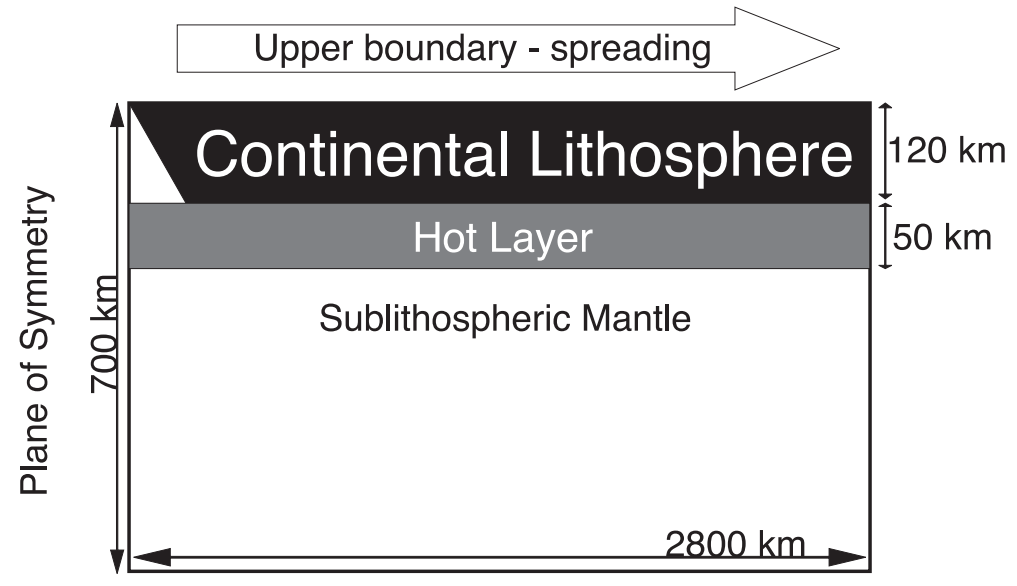

Fig. 2. Initial geometry of the solution space with the sub-lithospheric hot layer. The Continental lithosphere is pre-thinned by a factor of 2 over 3 horizontal elements to ensure localisation of the initial rift.

Watson and McKenzie Parameterisation

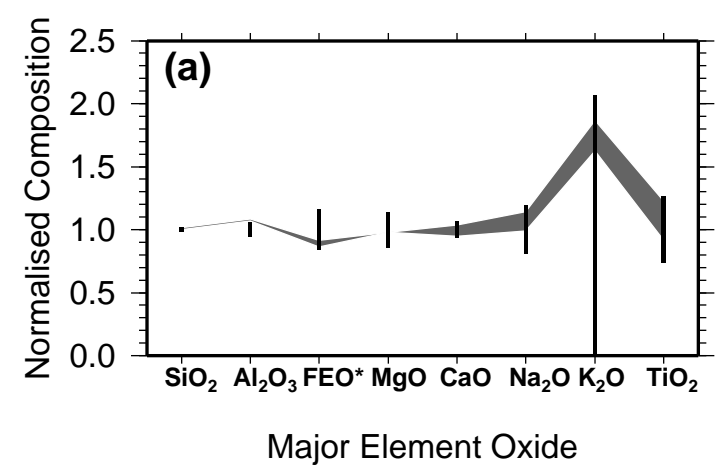

Niu Parameterisation

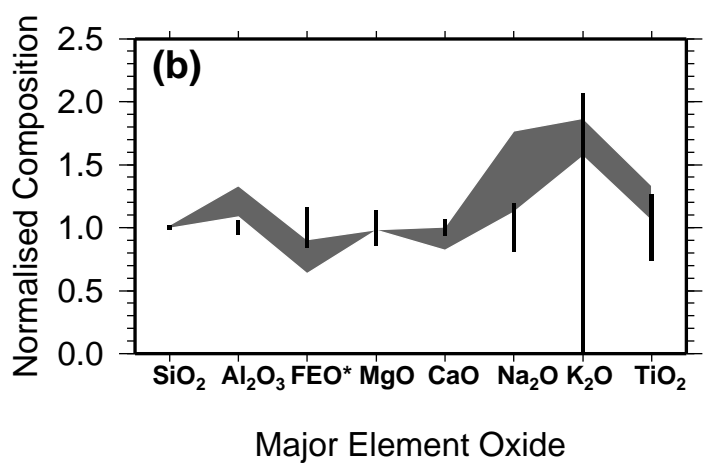

Fig. 3. Full range of steady state MORB predictions for (a) WM91 and (b) N97 models run at mantle temperatures of $1300^{\circ} \mathrm{C}$ and $1325^{\circ} \mathrm{C}$, and half spreading rates of $10 \mathrm{~mm} \mathrm{yr}^{-1}$ and $20 \mathrm{~mm} \mathrm{yr}^{-1}$. Elements are normalised to North Atlantic MORB taken from GERM (http://earthref.org/). Bars show the variation in the north Atlantic data set. 

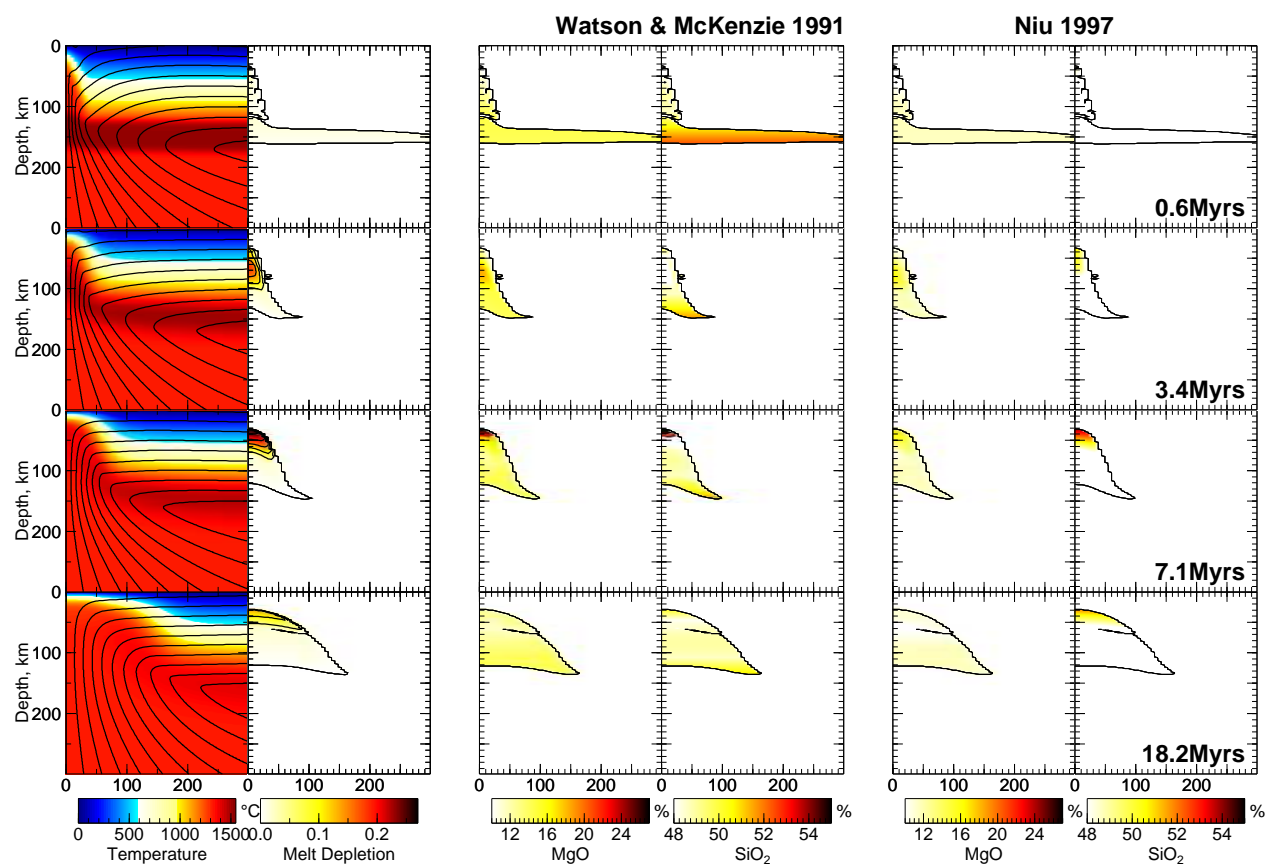

Fig. 4. Temperature and flow, melt depletion, instantaneous $\% \mathrm{MgO}$ and $\% \mathrm{SiO}_{2}$ composition of primary melt for WM91 [32] and N97 [33] parameterisation with a sub-lithospheric hot layer of $200^{\circ} \mathrm{C}$, mantle potential temperature of $1325^{\circ} \mathrm{C}$ and half spreading rate of $10 \mathrm{~mm} \mathrm{yr}^{-1}$. Plots show a region of $300 \times 300 \mathrm{~km}$. 


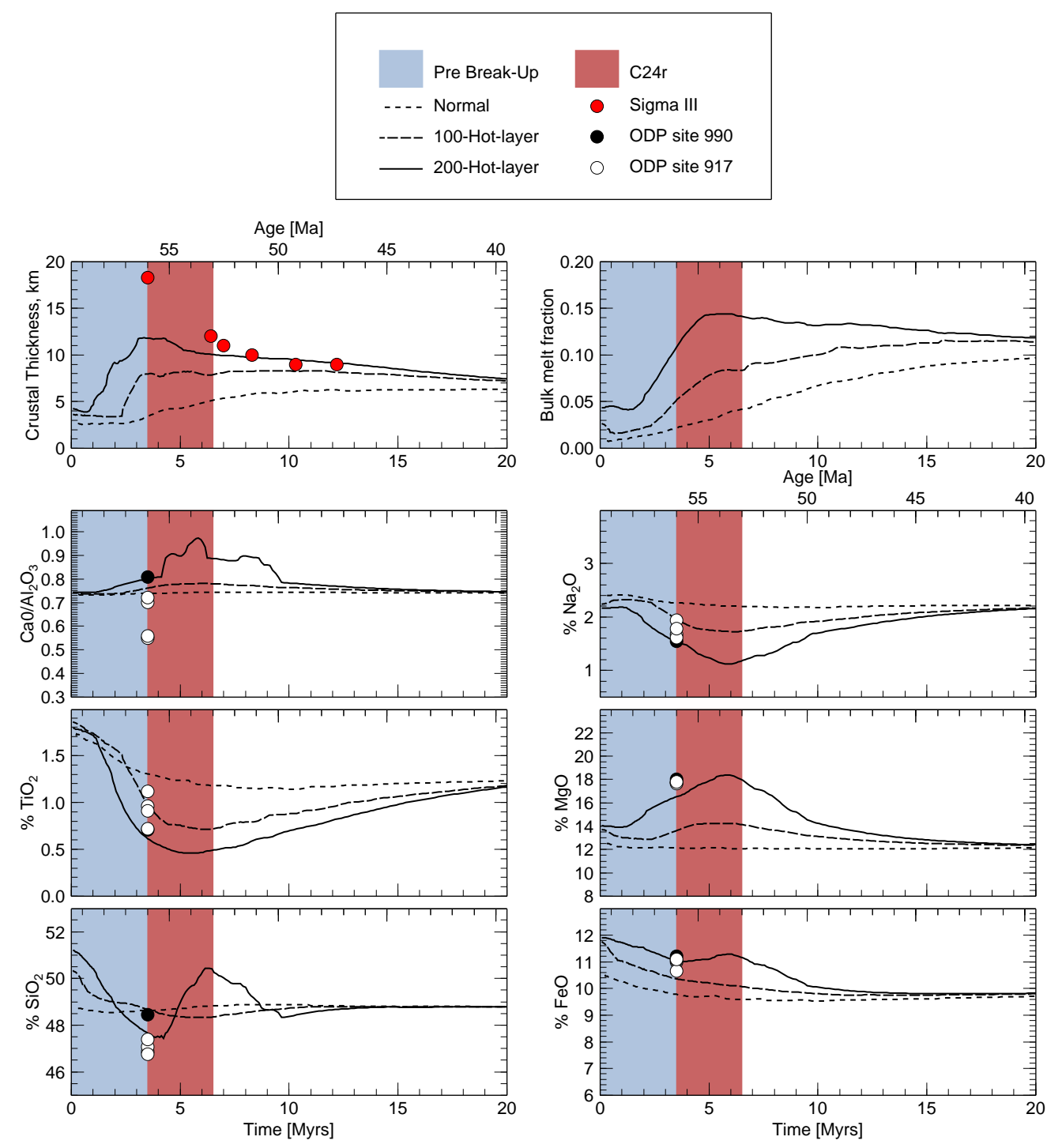

Fig. 5. Evolution of predicted igneous crustal thickness, bulk melt fraction and major element composition of primary melt for the WM91 parameterisation. The line plots show the prediction for a model without a sublithospheric hot layer, for a $100^{\circ} \mathrm{C}$ hot layer and a $200^{\circ} \mathrm{C}$ hot layer. The blue shaded area marks the time interval when melt is initially being produced in small quantities. 'breakup' occurs when there is a peak in melt production. The dark red shaded area represents the age rage of magnetic anomaly $\mathrm{C} 24 \mathrm{r}[17,18]$. The red circles show estimated crustal thickness from Holbrook et al. [12]. The black circles show primary composition from ODP site 990, the white circles show primary composition from ODP site 917 (see Table 1, [19,27,30]). 


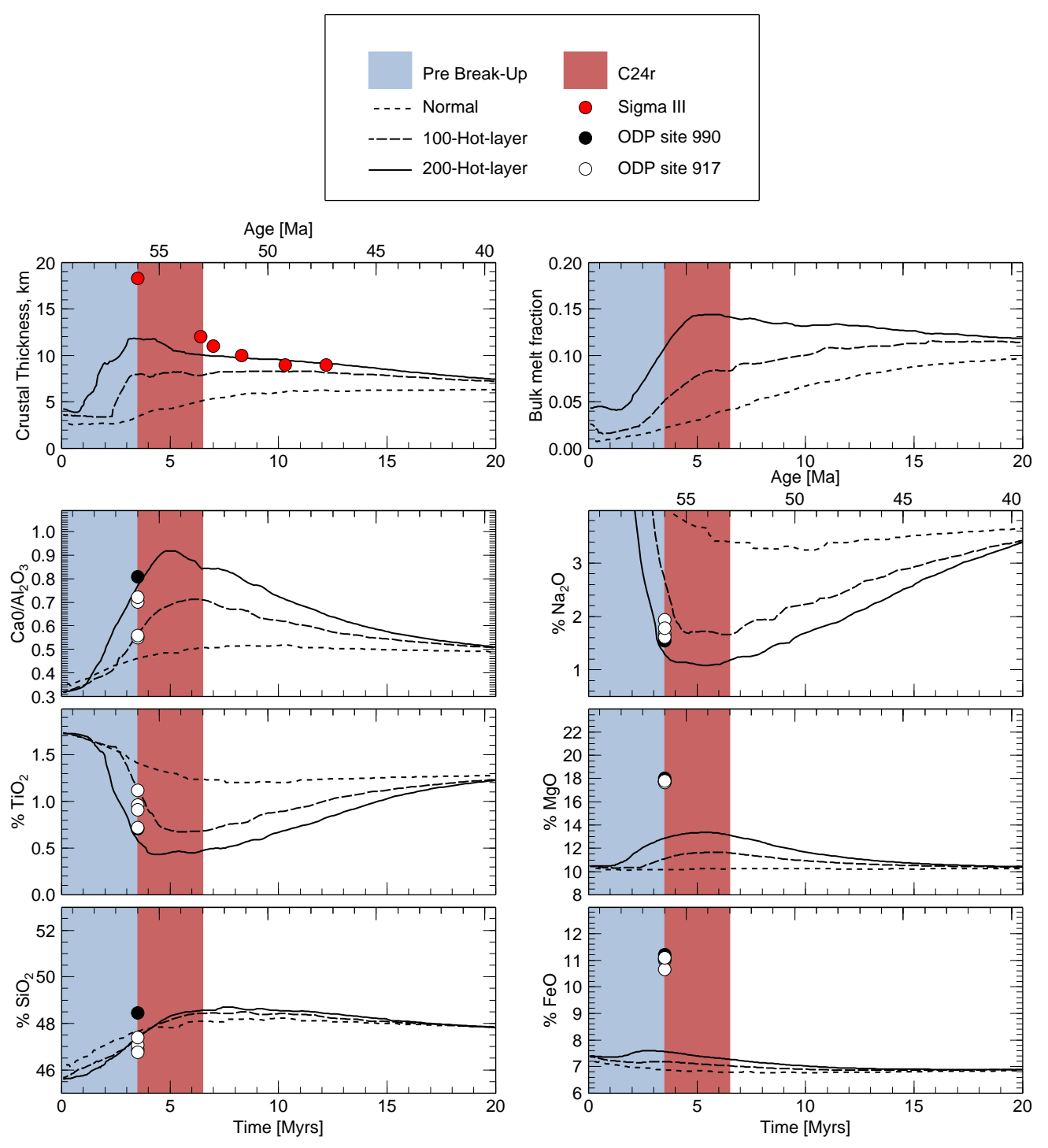

Fig. 6. Evolution of predicted crustal thickness and major element composition of primary melt for the N97 parameterisation. Other details as in Figure 5. 

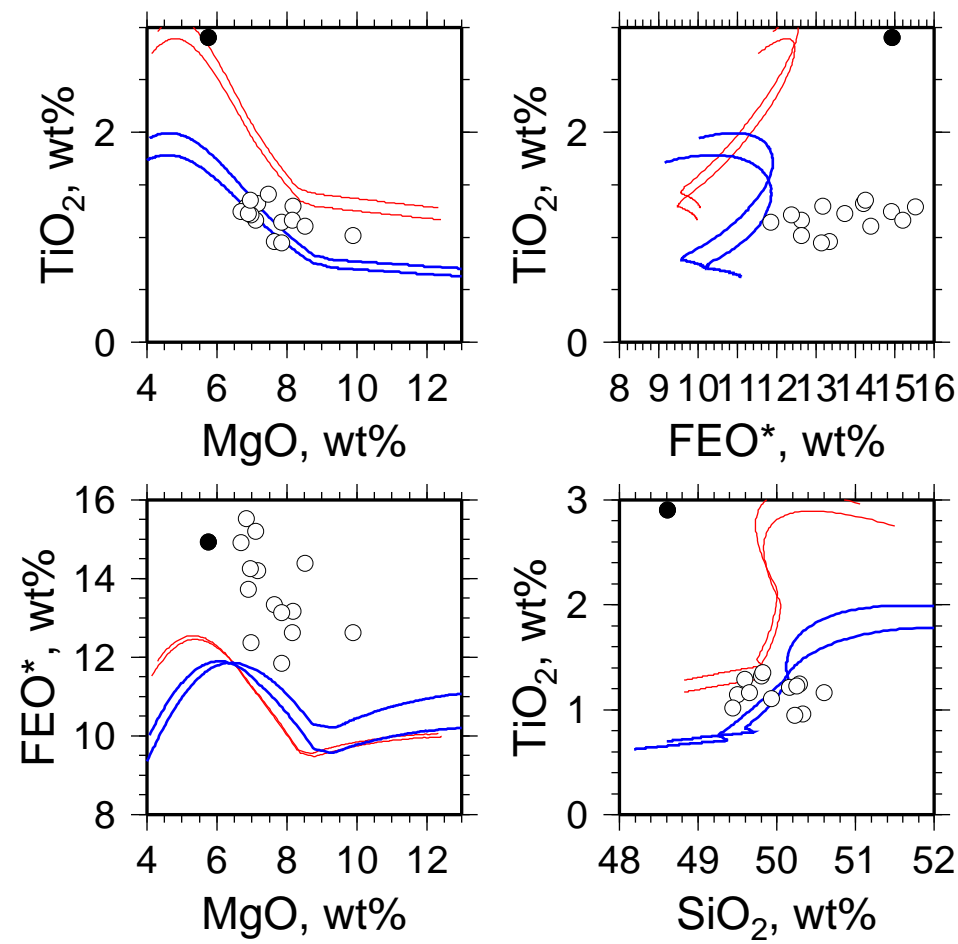

Fig. 7. Element ratios for magnesium, titanium, iron and silicon oxides. Plotted are the liquid lines of descent, red lines from steady state primary melts that were batch crystallised isobarically assuming magma pools at $200 \mathrm{MPa}$. Blue lines are from the peak magnesian primary melts similarly crystallised at $200 \mathrm{MPa}$, from 5 and $10 \mathrm{Myrs}$ model time (54.5 Ma and 49.5 Ma respectively). Open circles show seaward dipping reflector series (SDRS) composition data from ODP leg 152, site 918, the black circle shows the composition for the younger sill at site 918 [19]. 

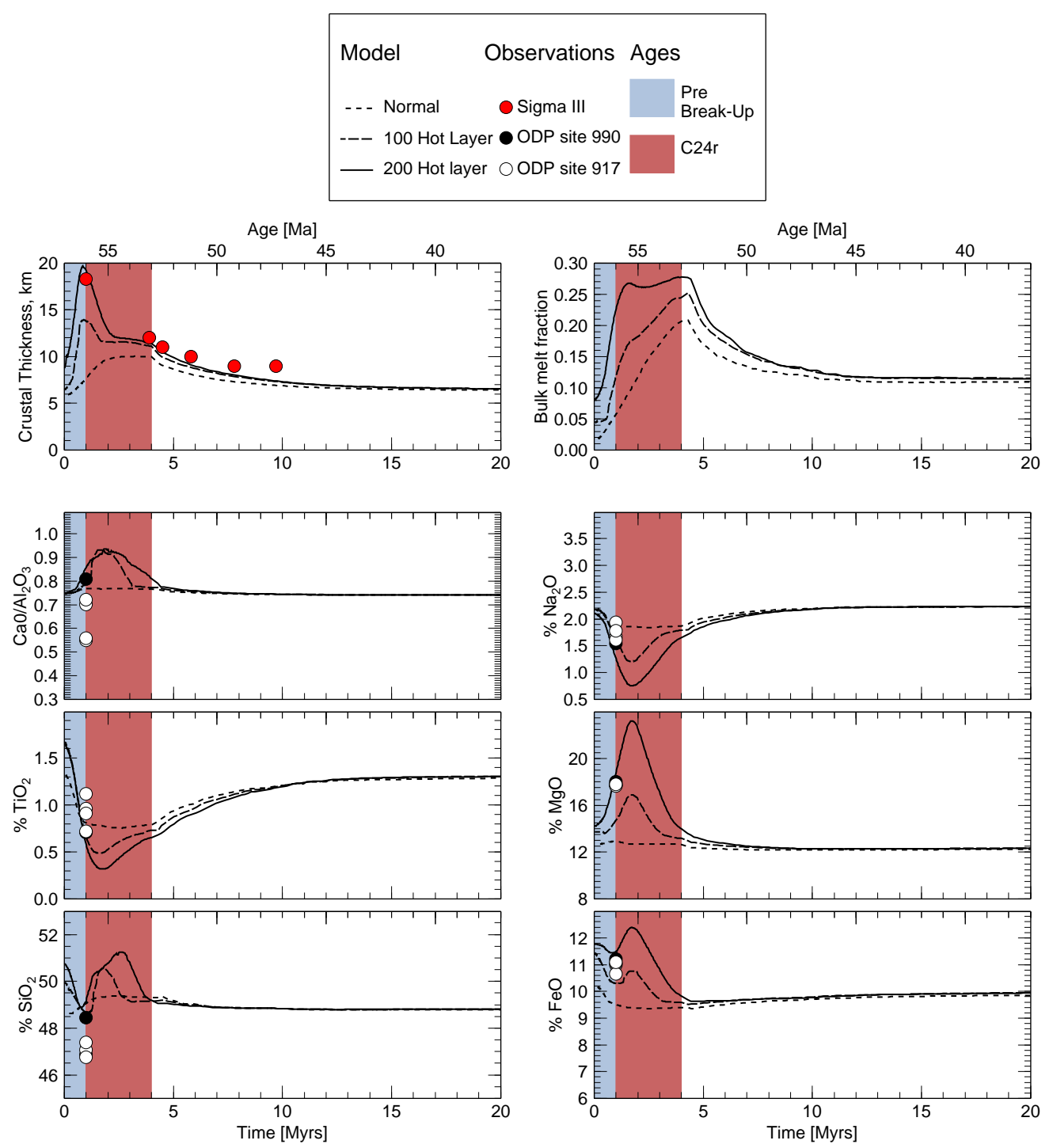

Fig. 8. Plot of predicted crustal thickness and major element composition of primary melt for the WM91 parameterisation with a variable spreading rate of $40 \mathrm{~mm} \mathrm{yr}^{-1}$ for the first $4 \mathrm{Ma}$ of evolution followed by constant spreading at $10 \mathrm{~mm} \mathrm{yr}^{-1}$. Other details as in Figure 5. 